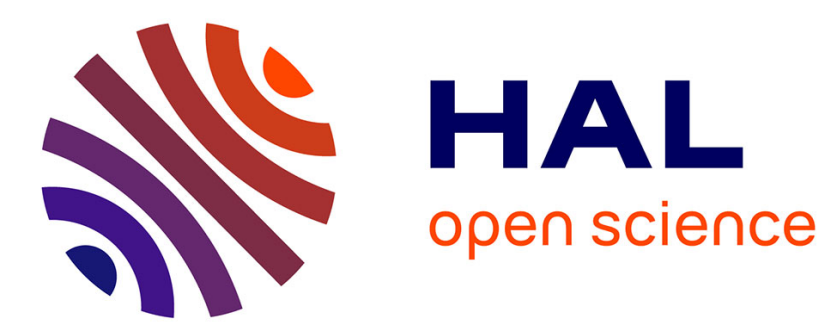

\title{
Compound Magnetic Wire Sensor Assembling Cylindrical Ba Ferrite Magnet
}

A. Matsushita, T. Ikenaga, S. Abe

\section{To cite this version:}

A. Matsushita, T. Ikenaga, S. Abe. Compound Magnetic Wire Sensor Assembling Cylindrical Ba Ferrite Magnet. Journal de Physique IV Proceedings, 1997, 07 (C1), pp.C1-163-C1-164. 10.1051/jp4:1997159 . jpa-00255106

\section{HAL Id: jpa-00255106 https://hal.science/jpa-00255106}

Submitted on 1 Jan 1997

HAL is a multi-disciplinary open access archive for the deposit and dissemination of scientific research documents, whether they are published or not. The documents may come from teaching and research institutions in France or abroad, or from public or private research centers.
L'archive ouverte pluridisciplinaire HAL, est destinée au dépôt et à la diffusion de documents scientifiques de niveau recherche, publiés ou non, émanant des établissements d'enseignement et de recherche français ou étrangers, des laboratoires publics ou privés. 


\title{
Compound Magnetic Wire Sensor Assembling Cylindrical Ba Ferrite Magnet
}

\author{
A. Matsushita, T. Ikenaga and S. Abe \\ Department of Electrical Engineering, Kanagawa University, 3-27 Rokkakubashi, Yokohama 221, Japan
}

\begin{abstract}
A new type of the compound magnetic wire sensor is developed. A search coil is wound around the wire which has a uniaxial magnetic anisotropy along the axis direction of the wire. In order to apply a negative magnetic field to the wire, two pieces of cylindrical Ba ferrite magnets are appended at the both ends of the wire. The sensor induces a constant pulse voltage of about $0.7 \mathrm{mV} /$ turn which is independent of the changing rate of the positive external exciting field. The sensor consisted of the compound magnetic wire and 3000 turns search coil induces a stable output voltage of about $2 \mathrm{~V}$. It is also advantageous that this simple-structure sensor can be fabricated at a low cost.
\end{abstract}

\section{INTRODUCTION}

A compound magnetic wire is made of Vicalloy (40wt $\% \mathrm{Fe}-50 \mathrm{Co}-10 \mathrm{~V})$ wire, which is a semi-hard magnetic material. And the wire is twisted around its axis. When an asymmetric external magnetic field, which consists of a negative set magnetic field and a positive reset magnetic field, is applied to the wire and the magnetization of soft layer is parallel to that of hard core, a large Barkhausen jump is induced as the output voltage. The output voltage is independent of the frequency of external magnetic field and a sharp pulse voltage with a half width of about 15-20 $\mu$ s. However in this case the sensor requires two kinds of magnets that have an opposite polarity and a different amplitude. If the output voltage is induced when only a reset field was applied to the wire, it's quite beneficial. In this article, a structure of a new magnetic sensor which performs with only a positive magnetic field is reported.

\section{STRUCTURE OF WIRE SENSOR AND MEASUREMENT METHOD}

The compound magnetic wire has a uniaxial magnetic anisotropy along the axis direction of the wire. And the coercive force of the wire is about 20 Oe in the outer shell near the surface called a soft layer and 60 Oe in the inner core of the wire called a hard core [1],[2]. The twisted wire has been reported that a coercive force of the surface shell is larger than that of the inner core of the Wiegand wire [3],[4]. In this point, the situation in the compound magnetic wire is opposite. The improvement study using different wires consisting of the alloy $\mathrm{Co}-\mathrm{V}-\mathrm{Fe}$ and $\mathrm{Ni}-\mathrm{Fe}$ have been also reported [5].

The compound magnetic wire used in the experiment is twisted vicalloy wire of $0.25 \mathrm{~mm}$ in diameter and $30 \mathrm{~mm}$ in length.

Fig. 1 shows a measurement method for a distribution output voltage. A pair of cylindrical $\mathrm{Ba}$ ferrite $\left(\mathrm{BaO}^{\circ} 6 \mathrm{Fe}_{2} \mathrm{O}_{3}\right)$ magnets are appended with opposing their $\mathrm{N}$ and $\mathrm{S}$ poles at the both ends of the compound magnetic wire. A magnet spacing is $\mathrm{d} \mathrm{mm}$. The magnets are 5 and $2.2 \mathrm{~mm}$ in outside and inside diameter, respectively and $2.6 \mathrm{~mm}$ in length. In this case, an amplitude of the negative magnet magnetic field Hmag varies with a measurement point. Thus a distribution of output voltage $\mathrm{Vs}$ is measured by 100 turns movable search coil of $1.5 \mathrm{~mm}$ in width on the wire. Measurement position $\mathrm{x}$ is a distance from the center of the wire to the center of the search coil.

Fig. 2 shows the wave form of the exciting magnetic field. The exciting field consists of a negative magnetic field Hmag and a positive external magnetic field Hex with a half-wave [Fig. 2(a)]. As a result, a composite field consists of the reset field Hr and the set field Hs is applied to the sensor as indicated in Fig. 2(b).

\section{EXPERIMENTAL RESULT AND DISCUSSION}

Fig. 3 shows a distribution of the magnetic field by two cylindrical ferrite permanent magnets. A magnetic field Hmag at the center of the wire is Hmag $=20$ Oe for a magnetic spacing $\mathrm{d}=21 \mathrm{~mm}$ and Hmag $=9$ Oe for $\mathrm{d}=30 \mathrm{~mm}$, respectively. 
Fig. 4 shows a distribution of the output voltage. The output voltage has its maximum value at the center of the wire and decreases with closer to the magnet. Because Hmag acts more strongly than the proper set field Hs with measuring point is closer to the magnet, $\mathrm{Hr}=\mathrm{Hex}-\mathrm{Hmag}$ decreases and an orienting magnetization of the hard layer becomes weak. Fig. 5 shows a hysteresis loop for the external field $\mathrm{Hex}=100 \mathrm{Oe}$ at a frequency of $50 \mathrm{~Hz}$. In the figure, it is observed that a sharp output voltage Vs with a large Barkhausen jump effect which corresponds to the jump A of the hysteresis loop.

It is composed that a sensor which consists of a wire of $30 \mathrm{~mm}$ in length and a 3000 turn search coil of $20 \mathrm{~mm}$ in width on the wire. When the external field Hex is constant at $100 \mathrm{Oe}$, the output voltage is about $2 \mathrm{~V}$. The output voltage is almost constant for the lower frequency below $0.1 \mathrm{~Hz}$. The jitter of the output voltage of the sensor is about $60 \mu \mathrm{s}$ at $\mathrm{Hex}=100 \mathrm{Oe}$.

\section{CONCLUSION}

Two pieces of cylindrical Ba ferrite magnets are attached at the both ends of the wire in order to apply negative set field Hs. With applying a positive reset field $\mathrm{Hr}$ to the wire, the distribution characteristic of the output voltage in each position by the search coil was examined. As a consequence, this new type of magnetic sensor with a simple structure can be fabricated at a low cost and perform successfully only with the positive external magnetic field.

\section{Acknowledgment}

The authors would like to thank Mr. Nobuyuki Hirota for his support in this work.

\section{References}

[1] A.Matsushita and S.Abe. "Studies Pules-Generating Effect of Ferromagnetic Wire," Trans. IEE of Japan, Vol.100-A, No.7, pp. 25-30 (1980)

[2] S.Abe and A.Matsushita. "Construction of Electromagnetic Rotation Sensor Using Compound Magnetic Wire and Measurement at Extremely Low Frequency Rotations, 'IEEE Trans. on Magnetics, Vol.30, No.6, pp. $4635-4637$ (1994)

[3] J.R.Wiegand. "Bistable Magnetic Device," U. S. PAT. No.3820090 (1972)

[4] P.E.Wigen. "Wiegand Wire; New Material for Magneticbased Devices," Electronics, 48, pp. $100-105$ (1975)

[5] C.Radeloff and G.Rauscher. "Pulse Generation with Short Composite Wires," IEEE Trans.on Magnetics, Vol.21, No.5, pp.1933-1935 (1985)

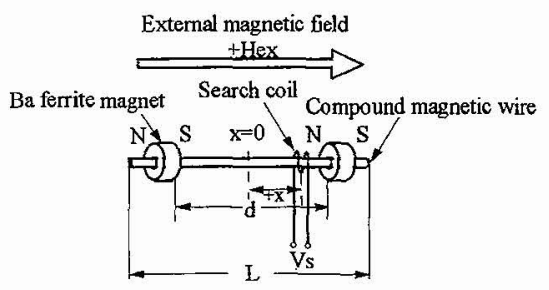

Fig.1 Measurement method for distribution output voltage

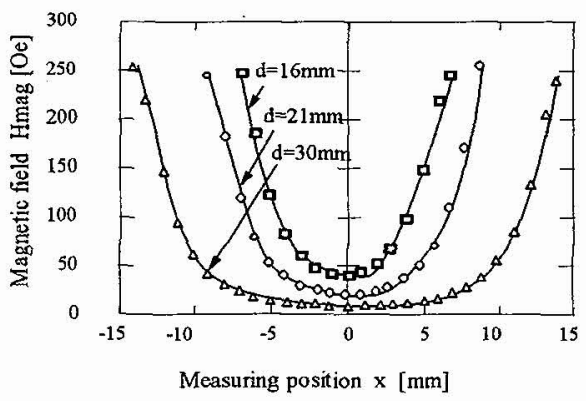

Fig.3 Distribution of magnetic field by two cylindrical ferrite permanent magnets

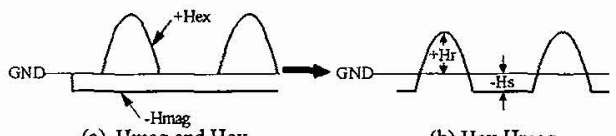

(a) Hmag and $\mathrm{Hex}$

(b) Hex-Hmag

Fig.2 Exciting magnetic field

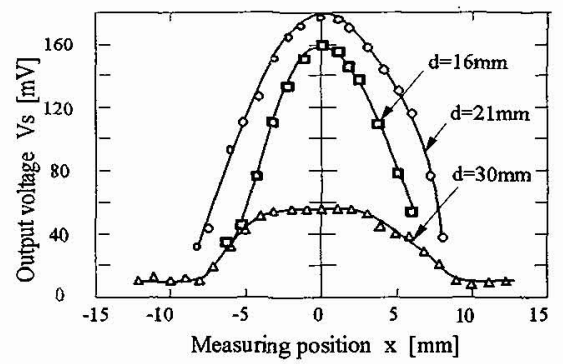

Fig.4 Distribution of Output voltage

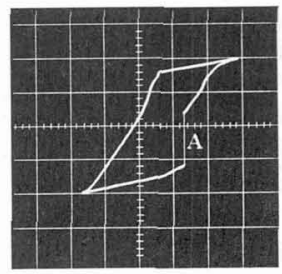

Fig.5 Hysteresis loop 